\title{
EXTRATO DE ALHO COMO ALTERNATIVA NA QUEBRA DE DORMÊNCIA DE GEMAS EM MACIEIRAS cv. FUJI KIKU ${ }^{1}$
}

\author{
RENATO VASCONCELOS BOTELHO² \& MARCELO MARQUES LOPES MÜLLER ${ }^{2}$
}

RESUMO - Este trabalho teve por objetivo estudar os efeitos do extrato de alho (Bioalhoß) na quebra de dormência de gemas de macieiras 'Fuji Kiku', em comparação ao uso convencional de cianamida hidrogenada $\left(\mathrm{H}_{2} \mathrm{CN}_{2}\right)$, na região de Guarapuava-PR. Logo após a poda de inverno, em setembro de 2005, os seguintes tratamentos foram pulverizados nas plantas durante o estádio fenológico de gema dormente: 1) Testemunha (sem tratamento); 2) EA (extrato de alho) 1\%; 3) EA 5\%; 4) EA 10\%; 5) OM (óleo mineral) 2\%; 6) EA $1 \%+\mathrm{OM} 2 \%$; 7) EA 5\% + OM 2\%; 8) EA $10 \%+\mathrm{OM} 2 \%$; 9) $\mathrm{H}_{2} \mathrm{CN}_{2} 0,4 \%+\mathrm{OM} 4 \%$. Os tratamentos com extrato de alho e óleo mineral apresentaram efeitos similares ao tratamento convencional com cianamida hidrogenada e óleo mineral, atingindo mais de $90 \%$ de brotação das gemas aos 50 DAT, enquanto o tratamento com óleo mineral isoladamente a $2 \%$ e a testemunha atingiram apenas 62,5 e $42,7 \%$, respectivamente. Os tratamentos com EA 5\% ou 10\%, com ou sem óleo mineral, foram os que apresentaram menores valores para as variáveis número de frutos, produção por planta e produtividade por área, não por ineficiência na quebra de dormência, mas, possivelmente, pela antecipação da floração que coincidiu com período bastante chuvoso no início da primavera.

Termos para indexação: Malus domestica, brotação, cianamida hidrogenada, fruticultura.

\section{GARLIC EXTRACT AS ALTERNATIVE ON BUD DORMANT BREAK OF APPLE TREES cv. FUJI KIKU}

\begin{abstract}
This study aimed to examine the effects of garlic extract (Bioalho®) on bud break of 'Fuji Kiku' apple trees in comparison to the conventional use of hydrogen cyanamide $\left(\mathrm{H}_{2} \mathrm{CN}_{2}\right)$ at the region of Guarapuava-PR, Brazil. Soon after winter pruning, in September 2005, the following treatments were sprayed on plants at dormant bud stage: 1) control (untreated); 2) $1 \%$ GE (garlic extract); 3) 5\% GE; 4) $10 \% \mathrm{GE} ; 5) 2 \% \mathrm{MO}$ (mineral oil); 6) 1\% GE + 2\% MO; 7) 5\% GE + 2\% MO; 8) 10\% GE + 2\% MO; 9) 0.4\% $\mathrm{H}_{2} \mathrm{CN}_{2}+4 \%$ MO. The treatments with garlic extract and mineral oil showed similar effects in comparison to the hydrogen cyanamide treatment, achieving up to $90 \%$ of bud sprouting at 50 DAT, while only $2 \%$ mineral oil and control, attained only 62.5 and $42.7 \%$, respectively. The treatments with 5 or $10 \%$ garlic extract presented the lowest values for number of fruits, yield per plant and yield per area, not because the ineffectivenessof break dormancy, but probably due to the antecipation of the flowering which coincided to a very much rainy period at the beginning of the spring.
\end{abstract}

Index terms: Malus domestica, sprouting, hydrogen cyanamide, fruitculture.

\section{INTRODUÇÃO}

As fruteiras de clima temperado caracterizam-se pela queda das folhas no final do ciclo vegetativo e entrada em dormência no inverno, permitindo a sua sobrevivência em condições de baixas temperaturas. Para que estas plantas iniciem um novo ciclo na primavera, é necessária a sua exposição a um período de frio, variável para cada espécie e cultivar (Petri et al., 1996).

No entanto, as cultivares de macieira mais plantadas no Sul do Brasil, como a Gala e a Fuji, assim como suas mutações, não têm suas exigências de frio plenamente satisfeitas, necessitando de tratamento com produtos químicos para a indução da brotação (Petri, 1997). Mesmo em regiões mais frias, como em São Joaquim-SC, a quebra de dormência artificial se faz necessária na maioria das vezes (Iuchi et al., 2004).

Muitos produtos apresentam efeito na superação da dormência, podendo ser citados: óleo mineral, cianamida hidrogenada, dinitro-ortho-cresol, dinitro-ortho-butil-fenol, calciocianamida, thidiazuron, entre outros. No entanto, atualmente no Brasil, somente o óleo mineral e a cianamida hidrogenada $\left(\mathrm{H}_{2} \mathrm{CN}_{2}\right)$ são registrados como indutores de brotação em macieiras (Petri et al., 2002). Em 2001, estimou-se que foram utilizados $112.490 \mathrm{~kg}$ de cianamida hidrogenada nos Estados Unidos e $36.300 \mathrm{~kg}$ na Itália, principalmente na cultura da videira (Settimi et al., 2005).

O uso de produtos químicos na quebra de dormência de plantas frutíferas de clima temperado é um fator preocupante devido à alta toxidade. A cianamida hidrogenada pode provocar ulcerações nos olhos, pele e trato respiratório, além de inibir a aldeído desidrogenase, levando à síndrome de acetaldeído (vômito, hiperatividade parassimpática, dispnéia, hipotensão e desorientação). AAgência de Proteção Ambiental (EPA) classifica o Dormex ${ }^{\circledR}\left(490 \mathrm{gL}^{-1} \mathrm{de}_{2} \mathrm{CN}_{2}\right)$ na mais alta categoria de toxicidade (categoria I) (Settimi et al., 2005). Esse alto risco de intoxicação pela exposição à cianamida hidrogenada levou à suspensão temporária das vendas do produto comercial Dormex ${ }^{\circledR}$ em 2002, na Itália, e revisão de sua regulamentação pelas autoridades da União Européia (Settimi et al., 2005).

Contudo, a necessidade de restringir cada vez mais o uso

(Trabalho 117-2006). Recebido em 16-08-2006. Aceito para publicação em 13-02-2007.

${ }^{2}$ Eng. Agr. Doutor. Professor Adjunto. Departamento de Agronomia, Universidade Estadual do Centro-Oeste - UNICENTRO. R. Simeão Camargo Varella de Sá nº 03, CEP 85040-080, Guarapuava-PR. E-mail: rbotelho@unicentro.br. 
de substâncias sintéticas na condução dos pomares, preconizada por sistemas sustentáveis de produção de frutas (isto é, Produção Orgânica e Produção Integrada), torna a questão da quebra de dormência química de plantas frutíferas um fator limitante para a atividade no Brasil (Sanhueza et al., 2003). Complementarmente, McArtney \& Walker (2004) relataram que uma das necessidades iminentes para a fruticultura orgânica é descobrir uma alternativa para a quebra de dormência de gemas, principalmente para as culturas de kiwi e maçã.

$\mathrm{Na}$ busca por novas alternativas para a quebra de dormência de plantas frutíferas de clima temperado, Kubota \& Miyamuki (1992) verificaram que a aplicação de pasta de alho na região do corte de poda de ramos de videiras 'Moscatel de Alexandria' estimulou a brotação de gemas de forma mais efetiva que a aplicação de solução a $20 \%$ de calciocianamida $\left(\mathrm{CaCN}_{2}\right)$, produto tradicionalmente utilizado na viticultura japonesa para esta finalidade. Em outro trabalho, Kubota et al. (2000) constataram que aplicações de pasta de alho puro ou óleo de alho a $20 \%$ promoveram a quebra de dormência de gemas sem apresentar sintomas de fitotoxidez, em videiras cv. Pione e Thompson Seedless.

Em trabalho desenvolvido por Sanchez (1992), verificouse que misturas de óleo mineral a $4 \%$ com extrato de alho a $2 ; 4$ ou $8 \%$, resultaram nos tratamentos mais efetivos para incrementar a brotação das gemas floríferas de ameixeiras cv. Santa Rosa. Por outro lado, Marodin \& Román (1997) não constataram qualquer efeito de extratos de alho na quebra de dormência de gemas de ameixeiras cv. Shiro, por se tratar de uma cultivar de difícil brotação natural, exigindo, possivelmente, concentrações mais elevadas deste produto.

Dentro deste contexto, este trabalho visou a desenvolver um método alternativo para a quebra de dormência de gemas de macieiras 'Fuji Kiku', utilizando-se de extrato de alho, compatível com os sistemas sustentáveis de produção de frutas, tais como a Produção Integrada (PI) e a Produção Orgânica (PO).

\section{MATERIAL E MÉTODOS}

Este experimento foi instalado em pomar comercial de macieiras 'Fuji Kiku' enxertadas no porta-enxerto 'EM-9', com três anos de idade, conduzido em sistema de líder central com copa estreita e no espaçamento de $1,1 \times 3,6 \mathrm{~m}$, situado em Guarapuava-PR (2533'S e 51'29'O, $1.095 \mathrm{~m}$ de altitude).

Os seguintes produtos comerciais foram utilizados para os tratamentos: Bioalho ${ }^{\circledR}$ (extrato de alho, Natural Rural S.A.), Attach ${ }^{\circledR}\left(75 \%\right.$ óleo mineral, Bayer Cropscience S.A.) e Dormex ${ }^{\mathrm{TM}}$ (490 $\mathrm{gL}^{-1} \mathrm{H}_{2} \mathrm{CN}_{2}$, Basf S.A.). O Bioalho® é um produto natural obtido da extração a frio do extrato de alho por prensagem, sendo totalmente solúvel em água.

Logo após a poda de inverno, em 19 de setembro de 2005, os seguintes tratamentos foram aplicados no estádio de gema dormente, com o uso de um pulverizador costal: 1) Testemunha (sem tratamento); 2) EA (extrato de alho) $1 \%$; 3) EA 5\%; 4) EA $10 \%$; 5) OM (óleo mineral) $2 \%$; 6) EA $1 \%+$ OM 2\%; 7) EA 5\% + OM $2 \%$; 8) EA $10 \%$ + OM $2 \%$; 9) $\mathrm{H}_{2} \mathrm{CN}_{2} 0,4 \%+\mathrm{OM} 4 \%$. Foram preparados 2,5 L de solução por tratamento, resultando na aplicação de cerca de $500 \mathrm{~mL}$ de solução por planta.

O delineamento experimental foi em blocos casualizados, com nove tratamentos, cinco repetições e parcela experimental constituída por uma planta. A colheita dos frutos foi realizada em 27 de março de 2006.

Para cada planta, foram avaliadas as seguintes variáveis: 1. Porcentagem de brotação - a porcentagem de gemas brotadas foi avaliada aos 30; 37; 43 e 50 dias após tratamentos (DAT). A brotação foi considerada a partir do estádio fenológico de "ponta verde". Foram contadas as gemas de cinco ramos previamente identificados de cada planta.

2. Número de frutos - contados por ocasião da colheita.

3. Produção por planta - os frutos foram pesados em balança eletrônica de precisão, sendo os resultados expressos em gramas. 4. Peso médio dos frutos - estimou-se o peso médio dos frutos a partir dos resultados de número de frutos e produção por planta, sendo os resultados expressos em gramas.

5. Teor de sólidos solúveis totais (SST) - a partir de uma amostra de dez frutos por planta, com auxílio de um refratômetro de bancada com autocompensação de temperatura, sendo expresso em porcentagem (Carvalho et al., 1990).

6. Acidez total titulável (ATT) - por titulação em uma alíquota de $10 \mathrm{~mL}$ do suco com $\mathrm{NaOH} 0,1 \mathrm{~N}$, sendo expressa em g de ácido málico por $100 \mathrm{~mL}$ de mosto (porcentagem p/v) (Carvalho et al., 1990).

7. Relação SST/ATT - estimado a partir dos resultados das análises químicas.

8. Firmeza da polpa - duas medições foram realizadas por fruto na região equatoriana após retirada da epiderme, com auxílio de um penetrômetro analógico com ponteira de $11 \mathrm{~mm}$, sendo os resultados expressos em $\mathrm{kg} \mathrm{pol}^{-2}$.

Todos os resultados foram submetidos à análise de variância. Para os dados de porcentagem de brotação, estudouse a interação entre os fatores doses de extrato de alho e uso de óleo mineral, e realizou-se análise de regressão polinomial. Para as demais variáveis, aplicou-se o teste de Tukey, ao nível de 5\% de probabilidade.

\section{RESULTADOS E DISCUSSÃO}

Aos 30 e 50 dias após os tratamentos (DAT), as doses de EA apresentaram efeito quadrático para a variável porcentagem de brotação das gemas de macieiras 'Fuji Kiku'. Além disso, o óleo mineral aumentou o efeito do EA na quebra de dormência, efeito este mais evidente quando adicionado à diluição de 1\% EA na avaliação realizada aos 50 DAT (Figuras 1 e 2). Aos 30 DAT, menos de $15 \%$ das gemas das plantas do tratamento-testemunha estavam brotadas, enquanto este valor foi de $66,7 \%$ e $85,1 \%$ para os tratamentos com EA $1 \%+$ OM $2 \%$ e EA $5 \%$ + OM $2 \%$, respectivamente (Figura 1). Aos 50 DAT, as plantas do tratamento- testemunha apresentavam apenas $42,7 \%$ de brotação, enquanto os tratamentos com EA + OM 2\% alcançaram valores acima de $90 \%$ (Figura 2). Pela maximização da função, a estimativa da dose de EA, quando adicionado OM $2 \%$ para a máxima porcentagem de brotação, foi de 6,5 e 6,6\% aos 30 e 50 DAT, respectivamente. 


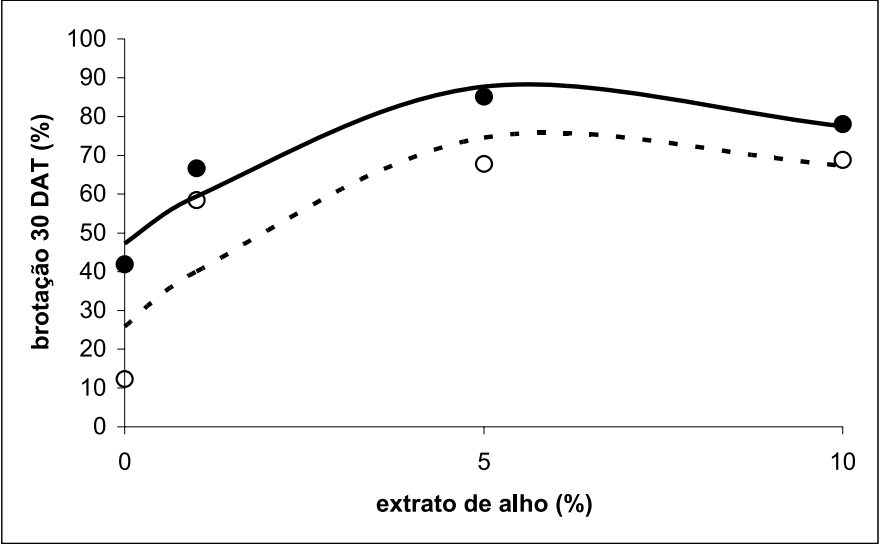

FIGURA 1 - Brotação (\%) de gemas de macieiras 'Fuji Kiku' tratadas com diferentes doses de extrato de alho sem adição de óleo mineral $(\mathrm{O} y=25,8672+15,3437 \mathrm{x}$ $\left.-1,1196 x^{2}, r^{2}=0,7285^{* *}\right)$ e com adição de óleo mineral a $2 \%\left(\bullet y=47,1686+13,2067 x-1,0177 x^{2}\right.$, $\left.\mathrm{r}^{2}=0,9178^{* *}\right)$ aos 30 dias após os tratamentos (Guarapuava-PR, 2005). (Significância do teste F para regressão polinomial: $* *=p>0,01)$

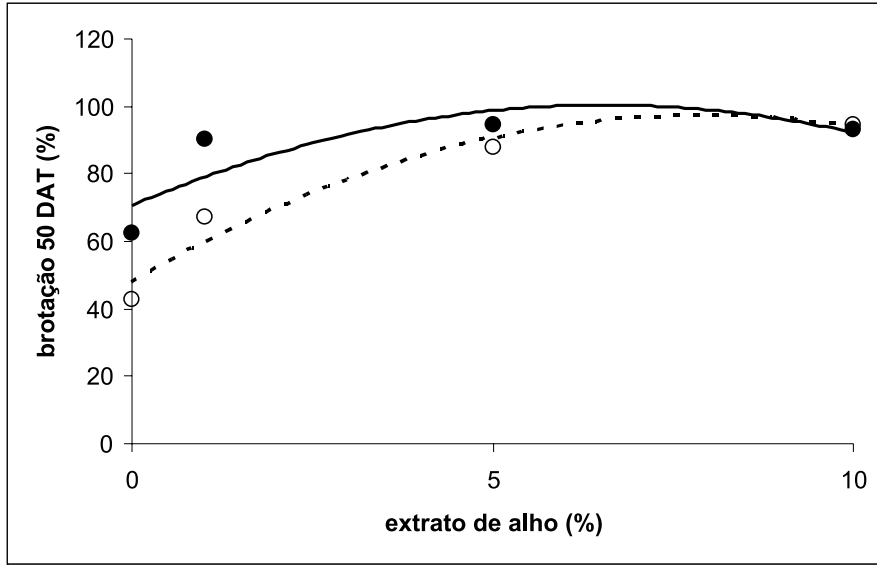

FIGURA 2 - Brotação (\%) de gemas de macieiras 'Fuji Kiku' tratadas com diferentes doses de extrato de alho sem adição de óleo mineral ( $\mathrm{y}$ y =48,1630 + 12,4340x $\left.-0,7841 \mathrm{x}^{2}, \mathrm{r}^{2}=0,9421^{* *}\right)$ e com adição de óleo mineral a $2 \%\left(\bullet y=70,6190+9,0983 x-0,6940 x^{2}, r^{2}\right.$ $\left.=0,6968^{* *}\right)$ aos 50 dias após ostratamentos (Guarapuava-PR, 2005). (Significância do teste F para regressão polinomial: $* *=p>0,01$ )

Os tratamentos com EA + OM $2 \%$ e o tratamento convencional com cianamida hidrogenada apresentaram efeitos similares na quebra de dormência de macieiras 'Fuji Kiku', atingindo mais de $90 \%$ de brotação aos 50 DAT. Por outro lado, os tratamentos-testemunha e OM $2 \%$ apresentaram valores de porcentagem de brotação significativamente inferiores aos demais durante todo o período de avaliação (Figura 3).

De maneira geral, a produção de frutos foi muito baixa para todos os tratamentos em função de um período bastante
TABELA 1 - Número de frutos, peso médio (g), produção por planta $(\mathrm{kg})$ e produtividade por área $\left(\mathrm{kg} \mathrm{ha}^{-1}\right)$ de macieiras 'Fuji Kiku'submetidas a diferentes tratamentos para quebra de dormência (Guarapuava-PR, 2005).

\begin{tabular}{lccc}
\hline Tratamentos & $\begin{array}{c}\text { Número } \\
\text { frutos }\end{array}$ & Peso frutos (g) & $\begin{array}{c}\text { Produção/planta } \\
(\mathbf{g})\end{array}$ \\
\hline Testemunha & $11,0 \mathrm{ab}^{(1)}$ & $124,87 \mathrm{ab}$ & $1345,3 \mathrm{ab}$ \\
EA 1\% & $13,5 \mathrm{ab}$ & $141,07 \mathrm{a}$ & $1951,8 \mathrm{ab}$ \\
EA 5\% & $9,0 \mathrm{ab}$ & $127,28 \mathrm{ab}$ & $1155,8 \mathrm{ab}$ \\
EA 10\% & $5,8 \mathrm{~b}$ & $137,77 \mathrm{ab}$ & $797,8 \mathrm{~b}$ \\
OM 2\% & $15,2 \mathrm{ab}$ & $141,57 \mathrm{a}$ & $2165,2 \mathrm{ab}$ \\
EA 1\%+ OM 2\% & $18,0 \mathrm{a}$ & $151,00 \mathrm{a}$ & $2724,8 \mathrm{a}$ \\
EA 5\%+ OM 2\% & $4,5 \mathrm{~b}$ & $139,39 \mathrm{a}$ & $623,2 \mathrm{~b}$ \\
EA 10\%+ OM 2\% & $6,5 \mathrm{ab}$ & $110,00 \mathrm{~b}$ & $726,5 \mathrm{~b}$ \\
H 2 CN 2 0,4\% + OM 4\% & $13,2 \mathrm{ab}$ & $138,17 \mathrm{ab}$ & $1864,2 \mathrm{ab}$ \\
Prob > F & 0,0104 & 0,00481 & 0,00338 \\
C.V. $(\%)$ & 47,20 & 9,07 & 48,35 \\
D.M.S. (5\%) & 12,20240 & 29,35713 & 1725,43609 \\
\hline
\end{tabular}

(1) Médias seguidas por letras iguais, em uma mesma coluna, não diferem entre si, pelo teste de Tukey, ao nível de 5\% de probabilidade.

TABELA 2 - Teor de sólidos solúveis (\%), acidez titulável (\%), relação sólidos solúveis/acidez titulável e firmeza da polpa $\left(\mathrm{kg} \mathrm{pol}^{-2}\right)$ de frutos de macieiras 'Fuji Kiku'submetidas a diferentes tratamentos para quebra de dormência (Guarapuava-PR, 2005).

\begin{tabular}{lcccc}
\hline Tratamentos & $\begin{array}{c}\text { Sólidos } \\
\text { Solúveis } \\
\text { Totais (\%) }\end{array}$ & $\begin{array}{c}\text { Acidez Total } \\
\text { Titulável (\%) }\end{array}$ & SST/ATT & Firmeza $\left(\mathbf{k g ~ p o l}^{-2}\right)$ \\
& $14,12 \mathrm{~ns}$ & $0,4228 \mathrm{~ns}$ & $34,20 \mathrm{~ns}$ & $8,02 \mathrm{~ns}$ \\
\hline Testemunha & 15,17 & 0,4044 & 38,12 & 8,03 \\
EA 1\% & 15,75 & 0,3936 & 40,52 & 7,88 \\
EA 5\% & 16,02 & 0,4041 & 40,70 & 8,89 \\
EA 10\% & 15,62 & 0,4301 & 37,09 & 8,56 \\
OM 2\% & 16,00 & 0,4439 & 36,07 & 8,65 \\
EA 1\%+ OM 2\% & 15,62 & 0,3876 & 40,80 & 8,35 \\
EA 5\%+ OM 2\% & 16,77 & 0,3603 & 47,25 & 8,08 \\
EA 10\% + OM 2\% & 15,00 & 0,3544 & 42,70 & 8,24 \\
$\mathrm{H}_{2}$ CN 2 0,4\% + OM 4\% & 0,1587 & 0,3537 & 0,2123 & 0,5287 \\
\hline Prob > F & 7,46 & 13,87 & 16,07 & 8,55 \\
C.V. (\%) & 2,79825 & 0,13349 & 15,3576 & 1,7078 \\
D.M.S. (5\%) & & & & \\
\hline
\end{tabular}

chuvoso no início da primavera, o que pode ter interferido na polinização das flores. De acordo com os dados da Estação Meteorológica da Unicentro, Guarapuava-PR, de 19 de setembro a 18 de outubro de 2005, a precipitação foi de $339,9 \mathrm{~mm}$. Particularmente, os tratamentos com EA 5\% e 10\%, com ou sem óleo mineral, tiveram uma redução muito acentuada da frutificação devido à maior antecipação da floração e, conseqüentemente, maior coincidência com este período chuvoso. $O$ tratamento EA $5 \%+$ OM $2 \%$ apresentou os menores valores para as variáveis 


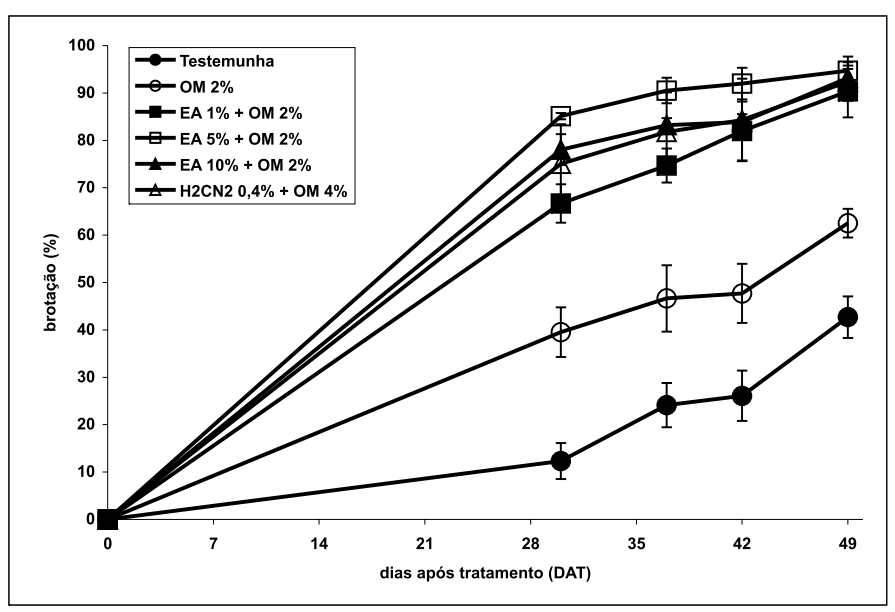

FIGURA 3 - Brotação (\%) de gemas de macieira 'Fuji Kiku' submetidas a diferentes tratamentos para quebra de dormência no estádio fenológico de gema dormente (barras verticais representam o desviopadrão. $\mathrm{n}=5$ ).

número de frutos e produção por planta, diferindo-se, significativamente, do tratamento EA $1 \%+\mathrm{OM} 2 \%$, que obteve os maiores valores. Embora tenha havido diferenças significativas, não foi possível estabelecer um padrão de comportamento da variável peso dos frutos em função dos tratamentos para quebra de dormência (Tabela 1).

Não houve diferenças significativas para as variáveis teor de sólidos solúveis totais, acidez total titulável, relação SST/ ATT e firmeza da polpa; no entanto, os maiores valores nominais da relação SST/ATT, dos tratamentos EA 5 ou $10 \%$ + OM $2 \%$ e $\mathrm{H}_{2} \mathrm{CN}_{2} 0,4 \%+\mathrm{OM} 4 \%$, sugerem seus efeitos na antecipação da maturação dos frutos (Tabela 2).

Em 2005, a macieira 'Fuji Kiku' não teve sua necessidade de frio satisfeita na região de Guarapuava-PR. Essa cultivar precisa de 1.040 unidades de frio pelo Método da Carolina do Norte para a superação da dormência (Chariani \& Stebbins, 1994) e, nesse inverno, foram acumuladas apenas 902,2 unidades. Por essa razão, as plantas não-tratadas apresentaram apenas 42,7\% das gemas brotadas aos 50 DAT.

A eficácia da mistura de cianamida hidrogenada e óleo mineral na quebra de dormência de macieiras 'Fuji Kiku', verificada neste experimento, já era, de certa forma, esperada, considerando que este é o tratamento convencional para esta finalidade no Brasil. No entanto, a busca por novos agentes de quebra de dormência é essencial devido à alta toxicidade da cianamida hidrogenada (Settimi et al., 2005). Por outro lado, o Bioalho®é um produto natural, recomendado para sistemas de produção orgânica, de acordo com a legislação brasileira atual, sendo obtido pela extração a frio do extrato de alho por prensagem.

Neste experimento, as misturas de extrato de alho e óleo mineral foram similares ou superiores ao tratamento convencional para quebra de dormência de macieiras 'Fuji Kiku'. Resultados similares foram verificados com compostos à base de alho em videiras (Kubota \& Myamuki, 1992; Kubota et al., 2000) e ameixeiras (Sanchez, 1992). De acordo com Kubota et al. (1999), as substâncias ativas no alho, responsáveis pela quebra de dormência de gemas, são compostos voláteis contendo enxofre e com um grupo alil $\left(\mathrm{CH}_{2} \mathrm{CHCH}_{2}\right)$, principalmente o dialil dissulfito, que é o sulfito mais abundante no alho.

Os tratamentos com extrato de alho e óleo mineral a $2 \%$ foram os mais efetivos na quebra de dormência, conferindo mais de $90 \%$ de gemas brotadas de macieiras 'Fuji Kiku'. O tratamento com $1 \%$ de extrato de alho e óleo mineral a $2 \%$ foi análogo ao tratamento convencional com cianamida hidrogenada; no entanto, novas investigações utilizando maiores doses de óleo mineral poderão permitir a redução da dose de Bioalho® e aumentar a efetividade e a competitividade do seu uso para quebra de dormência de macieiras e de outras espécies de plantas frutíferas de clima temperado.

\section{CONCLUSÕES}

1. Misturas de extrato de alho entre 1 e $10 \%$ e óleo mineral a $2 \%$ apresentam efeito similar ao tratamento convencional com cianamida hidrogenada e óleo mineral na quebra de dormência de macieiras 'Fuji Kiku', na região de Guarapuava-PR.

2. A aplicação de extrato de alho a $1 \%$ e óleo mineral a $2 \%$, através da pulverização no estádio de gema dormente, pode ser recomendada para a quebra de dormência de macieiras 'Fuji Kiku', na região Guarapuava-PR, sendo um método economicamente viável e adequado para os sistemas de produção orgânica e integrada.

\section{AGRADECIMENTOS}

Ao Sr. Reinhardt Kratz, pela concessão da área do pomar comercial em Guarapuava-PR, para a condução deste projeto de pesquisa, e ao Instituto Tecnológico SIMEPAR, pelos dados meteorológicos fornecidos provenientes de sua Estação Meteorológica, em Guarapuava-PR.

\section{REFERÊNCIAS}

CARVALHO, C.R.L.; CARVALHO, P.R.N.; MANTOVANI, D.M.B.; MORAES, R.M. Análise química de alimentos. Campinas: ITAL, 1990. 121p.

CHARIANI, K.; STEBBINS, R.L. Chilling requirements of apple and pear cultivars. Fruit Varieties Journal, Blacksburg, v.48, p.215-222, 1994.

IUCHI, V.L.; IUCHI, T.; BRIGHENTI, E. et al. Quebra de dormência da macieira (Malus domestica Borkh) em São Joaquim-SC. Revista Brasileira de Fruticultura, Jaboticabal, v.24, p.168174, 2004.

KUBOTA, N.; YASUSHI, Y.; KOJI, T.; KAZUYOSHI, K.; TESUO, H.; SHOJI, N. () Identification of active substances in garlic responsible for breaking bud dormancy in grapevines. Journal of the Japanese Society for Horticultural Science, Kyoto, v.68, p.1.111-1.117, 1999.

KUBOTA, N.; MATTHEWS, M.A.; TAKAHAGI, T. et al. Effects of garlic preparations and calcium and hydrogen cyanamides on budbreak of grapevines grown in greenhouses. American Journal of Enology and Viticulture, Davis, v.51, p.409-414, 2000. 
KUBOTA, N.; MIYAMUKI, M. Breaking bud dormancy in grapevines with garlic paste. Journal of the American Society for Horticultural Science, Alexandria, v.117, p.898901, 1992.

MARODIN, G.A.B.; ROMÁN, A.E.C. A cianamida hidrogenada, o oleo mineral e o extrato de alho na quebra de dormência e produção da ameixeira 'Shiro' em Texcoco - México. Pesquisa Agropecuária Gaúcha, Porto Alegre, v.3, p.177-181, 1997.

MCARTNEY, S.J.; WALKER, J.T.S. Current situation and future challenges facing the production and marketing of organic fruit in Oceania. Acta Horticuturae, Leuven n.638, p.387396, 2004.

PETRI, J.L.; PALLADINI, L.A.; SCHUCK, E. Dormência e indução da brotação de fruteiras de clima temperado. Florianópolis: EPAGRI, 1996. 110p. (Boletim técnico, 75)

PETRI, J.L. Indução de brotação de macieira por cianamida hidrogenada e óleo mineral sob influência da temperatura. Pesquisa Agropecuária Brasileira, Brasília, v.32, p.71-75, 1997.

PETRI, J.L.; PALLADINI, L.A.; POLA, A.C. Dormência e indução da brotação da macieira. In: EPAGRI. Manual da cultura da macieira. Florianópolis: EPAGRI, 2002. p.261-298.

SANCHEZ, E.S. Evaluación del extrato de ajo como estimulador de la brotación en ciruelo japonés, Prunus salicina L. 'Santa Rosa'. 1992. 63F. Dissertação (Mestrado em Fruticultura) Colegio de Postgraduados, Centro de Fruticultura, Texcocco, 1992.

SANHUEZA, R.M.V.; ANDRIGUETO, J.R.; KOSOSKI, A.R. Situação atual da produção integrada de frutas no Brasil. In: MELO, G.W.B.; SEBBEN, S.S. (Ed.). SEMINÁRIO BRASILEIRO DE PRODUÇÃO INTEGRADADE FRUTAS, 5., Bento Gonçalves, 2003. Anais. Bento Gonçalves: EmbrapaCNPUV, 2003. p. 23-25

SETTIMI, L.; DAVANZO, F.; FARAONI, MICELI, G.; RICHMOND, D.; CALVERT, G.M. Update: Hidrogen Cyanamide-related Ilnesses-Italy, 2002-2004. Morbidity and Mortality Weekly Report, Atlanta, v.54, p.405-408, 2005. 